\title{
Serum klotho: a potential predictor of cerebrovascular disease in hemodialysis patients
}

\author{
Honglan Wei ${ }^{\dagger}$, Hua Li ${ }^{\dagger}$, Xiaohong Song, Xingguo Du, Yuan Cai, Chengxu Li, Liping Dong and Junwu Dong ${ }^{*}$
}

\begin{abstract}
Background: Hemodialysis patients suffer from a serious threat of cerebrovascular disease. Klotho, as an agingsuppressor gene, contributes to protect on vascular calcification and oxidative stress, which are the risk factors of cerebrovascular disease. The purpose of the present study is to determine the relationship between serum klotho and cerebrovascular disease in patients receiving hemodialysis.
\end{abstract}

Methods: Serum klotho levels of hemodialysis patients were measured by ELISA. Cerebrovascular diseases were diagnosed by CT or MRI scans. The cognitive function of hemodialysis patients with cerebrovascular disease were evaluated with a neuropsychological battery assessing domains of global cognition verbal memory, spatial memory, executive function and verbal fluency.

Results: Eighty-eight patients were included, $57 \pm 14$ years, 63.64\% male, 52.27\% older than 60 years. Twenty-eight participants had cerebrovascular disease (23 cases had cerebral infarction, 5 cases had cerebral hemorrhage). The average level of serum klotho of all participants was $119.10 \pm 47.29 \mathrm{pg} / \mathrm{ml}$. The serum klotho level was significantly associated with cerebrovascular disease in hemodialysis patients $(\mathrm{HR}(95 \% \mathrm{Cl})=0.975(0.960-0.990), p=0.001)$. The optimal cut-off value of serum klotho for predicting cerebrovascular disease in hemodialysis patients was $137.22 \mathrm{pg} /$ $\mathrm{ml}$, with a specificity of $96.4 \%$ and a sensitivity of $46.7 \%$. But serum klotho was not an independent risk factor of cognitive impairment for hemodialysis patients with cerebrovascular disease $(\mathrm{HR}((95 \% \mathrm{Cl})=1.002(0.986-1.018)$, $p=0.776)$ or with cerebral infarction $(\mathrm{HR}(95 \% \mathrm{Cl})=1.005(0.987-1.023), p=0.576)$.

Conclusions: The serum klotho level is a potential predictor of cerebrovascular disease in hemodialysis patients, but it is not an independent risk factor of cognitive impairment for hemodialysis patients with cerebrovascular disease.

Keywords: Hemodialysis, Klotho, Cerebrovascular disease, Cognitive impairment

\section{Background}

Over the past decade, chronic kidney disease (CKD), defined as a decreased glomerular filtration rate or increased albuminuria is recognized as a worldwide important public health problem, which is highly prevalent in developing countries. China is the largest developing country. In Chinese adults, the prevalence of CKD is $10.8 \%$ [1]. It means that there are about 119.5 million Chinese aged 18 years or older have CKD [1]. With the

\footnotetext{
* Correspondence: zdhping@163.com

+Honglan Wei and Hua Li contributed equally to this work.

Department of Nephrology, Puai Hospital, Tongji Medical College, Huazhong

University of Science and Technology, Wuhan, Hubei 430033, People's
}

Republic of China prevalence of CKD, end-stage renal disease (ESRD) has become an emerging worldwide health burden because of its many complications, high costs and mortality risk. Renal replacement therapy, containing hemodialysis, peritoneal dialysis and kidney transplant, is the main treatment for end-stage renal disease currently. There are about 2.2 million end-stage renal disease patients receiving renal replacement therapy, and hemodialysis accounts for $89 \%$. In China, 454,000 patients are receiving hemodialysis in 2016, where the number is 276,008 in 2011.

Hemodialysis is associated with raised risk of cardiovascular disease (CVD), infection, cerebrovascular 
disease and other complications. The risk of cerebrovascular disease in patients receiving hemodialysis is six to ten times higher than in the general population [2]. Cerebrovascular disease is the third leading cause of death for patients on dialysis [3]. In excess of 35\% dialysis patients with cerebrovascular disease experience short-term mortality [4]. Except that, disability and cognitive impairment are very common in survivors $[5,6]$. Cerebrovascular disease is prevalent in hemodialyis patients partly related to the traditional risk factors, such as age, hypertension, diabetes mellitus and dyslipidemia. The uremic and dialysis process itself also the independent risk factors for cerebrovascular disease $[7,8]$.

Calcium-phosphate imbalance plays a crucial role in vascular calcification, which is the risk factor of cerebrovascular disease. Klotho protein, which is predominantly expressed in the kidney and brain, has a unique role in renal calcium and phosphorus metabolism [9-11]. Furthermore, klotho contributes to protect on vascular calcification and oxidative stress $[12,13]$. Therefore, decreased klotho protein could be a novel non-traditional risk factor for cerebrovascular disease in hemodialysis patients.

Based on the strong vascular-protective effects of klotho, the current study aimed to confirm the relationship between serum klotho and cerebrovascular disease in patients receiving hemodialysis. It is hypothesized that decreased serum klotho protein is the novel risk factor of cerebrovascular disease in hemodialysis patients.

\section{Methods}

\section{Participants}

From November 2014 to March 2015, we recruited participants from the Dialysis Center in Puai hospital of Tongji medical college, Huazhong University. Eligible participants were 18 years or older, receiving maintenance hemodialysis for at least 3 months, and had undergone head CT or MRI examination in the past 1 year which excluded the history of stroke or silent brain infarction (SBI). Cerebral hemorrhage caused by craniocerebral trauma during the study and patients with stroke history were excluded. Patients were also excluded if they had an active psychiatric disorder, Alzheimer's disease, or if they had significant visual or hearing impairment. Serum klotho measurement and other laboratory studies were carried out at the beginning of the study. Every participant was followed up for 24 months. If the participants have stroke symptoms, head CT or MRI were scanned immediately. The others without stroke symptoms during the following time, head MRI were carried out in the last month of the study.

\section{Cerebrovascular disease}

Cerebrovascular diseases, including clinical stroke and SBI, were diagnosed by two neurology specialists and two imaging specialists. Clinical stroke were diagnosed through head CT or MRI scans and clinical symptoms which contain sudden onset of unilateral numbness, unilateral weakness, loss of ability to communicate, loss of ability to understand, loss of vision, and loss of half the visual field. SBI was diagnosed through MRI.

\section{Laboratory studies}

The fasting blood samples were collected in the morning and pre-dialysis. After collection, the blood samples were centrifuged immediately, serum and plasma were obtained and stored at $-80^{\circ} \mathrm{C}$. Serum klotho was detected by ELISA [14, 15], and antibodies were purchased from Xinfan Bio technology company, Shanghai, China. Automatic biochemical analyzer (Mindray, Shenzhen, China) was used for measuring albumin (ALB), calcium (Ca), phosphate $(\mathrm{P})$, iron, total iron binding capacity (TIBC), total cholesterol (Tch), triglycerides (TG), and highdensity lipoprotein cholesterol (HDL-C) concentrations and Low-density lipoprotein cholesterol (LDL-C). Hemoglobin $(\mathrm{Hb})$ was measured by Automatic blood analyzer (Mindray, Shenzhen, China). Serum ferritin (SF) and parathyroid hormone (PTH) was measured by Radioimmunoassay (Beckman Coulter, California, USA).

\section{Cognitive function}

All the patients with cerebrovascular disease were evaluated cognitive function with a neuropsychological battery assessing domains of global cognition verbal memory, spatial memory, executive function and verbal fluency. Global cognition was assessed with the mini-mental state examination (MMSE). Verbal memory was assessed with the Hopkins Verbal Learning Test-Revised (HVLT-R) immediate and delayed recall components [16]. Spatial memory was assessed with the Brief Visuospatial Memory Test-Revised (BVMT-R) [17]. Executive function was assessed with the Trail A test [18]. Verbal fluency was assessed with the Verbal Fluency Test (VFT) [19]. Cognitive impairment was defined as a score at least $1.5 \mathrm{SD}$ below normative values for age in 2 or more cognitive domains [20].

\section{Statistical analysis}

Datas with non-normal distribution were expressed as medians and interquartile ranges (25th and 75th percentiles) or percentages for categorical variables, while others with normal distribution were expressed as mean $\pm \mathrm{SD}$. We compared characteristics of patients with cerebrovascular disease to those without using the 2-tailed Student's $t$-test. Categorical data are presented as numbers and percentages and compared using the Chi-square test.

Cox regression analysis was used to explore the independent risk factors of cerebrovascular disease in hemodialysis patients. A receiver operating characteristic 
(ROC) curve was performed to examine the prognostic utility of serum klotho and to identify the optimal cut-off value.

The relationship between klotho and cognitive function of patients with cerebrovascular disease was explored using Cox regression models: model 1, crude model; model 2 , additionally adjusting for age; model 3 , additionally adjusting for diabetes mellitus (DM).

The correlations between the different parameters and klotho levels were evaluated using a correlation test.

All statistical analyses were performed using SPSS (version 20, IBM Corp, Amonk, NY, USA). A $p$-value $<0.05$ was considered statistically significant.

\section{Results}

\section{Participants' characteristics}

A total of 185 patients were screened. The hemodialysis patients with stroke history $(n=20)$ or without head CT or MRI in the past 1 year to certify who had no stroke or silent brain infarction were excluded $(n=15)$. Patients were also excluded if they had an active psychiatric disorder $(n=2)$, Alzheimer's disease $(n=18)$, or if they had significant visual or hearing impairment $(n=24)$.
Eighteen patients refused to participate in the study. A total of 88 hemodialysis patients were included for the current study, and 56(63.64\%) cases were male. The average age of the participating patients was $57 \pm 14$ years, and $46(52.27 \%)$ patients were older than 60 years. 34 (38.64\%) cases had diabetes mellitus. Of the participants, $28(31.82 \%)$ had cerebrovascular disease (23 had cerebral infarction, 5 had cerebral hemorrhage). The time between the serum klotho measurement and the cerebrovascular disease event was $16.86 \pm 8.29$ months. In the patients with cerebrovascular disease, $20(71.43 \%)$ cases were male, $15(53.57 \%)$ cases had diabetes mellitus, and $23(82.14 \%)$ cases were older than 60 years. The clinical characteristics of participants with cerebrovascular disease were very similar to participants without cerebrovascular disease, except for age and PTH (Table 1). The average level of serum klotho of all participants was $119.10 \pm 47.29$ $\mathrm{pg} / \mathrm{ml}$. As compared to the patients without cerebrovascular disease, serum klotho level was significantly lower in the participants with cerebrovascular disease $(91.65 \pm 28.19 \mathrm{pg} / \mathrm{ml}$ versus $131.90 \pm 49.09 \mathrm{pg} / \mathrm{ml}$, $P=0.000)$ (Table 1).

Table 1 Characteristics of participants

\begin{tabular}{|c|c|c|c|}
\hline & $\begin{array}{l}\text { Total } \\
(n=88)\end{array}$ & $\begin{array}{l}\text { With } \\
\text { cerebrovascular disease } \\
(n=28)\end{array}$ & $\begin{array}{l}\text { Without } \\
\text { cerebrovascular disease } \\
(n=60)\end{array}$ \\
\hline Age, years & $57 \pm 14$ & $66 \pm 10$ & $54 \pm 14^{* *}$ \\
\hline Male, n (\%) & $56(63.64 \%)$ & $20(71.43 \%)$ & $36(60 \%)$ \\
\hline Diabetes history, n (\%) & $34(38.64 \%)$ & $16(57.14 \%)$ & $18(30 \%)$ \\
\hline Hypertension, n (\%) & $72(81.82 \%)$ & $24(85.71 \%)$ & $48(80 \%)$ \\
\hline Tobacco smoking, n (\%) & $12(13.64 \%)$ & $4(14.29 \%)$ & $8(13.33 \%)$ \\
\hline HD vintage (months) & $34.55 \pm 18.57$ & $40.86 \pm 17.09$ & $31.60 \pm 18.63$ \\
\hline Klotho (pg/ml) & $119.10 \pm 47.29$ & $91.65 \pm 28.19$ & $131.90 \pm 49.09^{* *}$ \\
\hline $\mathrm{Hb}(\mathrm{g} / \mathrm{L})$ & $99.94 \pm 15.34$ & $100.93 \pm 13.12$ & $99.48 \pm 16.36$ \\
\hline $\mathrm{Ca}(\mathrm{mmol} / \mathrm{L})$ & $2.19 \pm 0.25$ & $2.20 \pm 0.23$ & $2.18 \pm 0.26$ \\
\hline $\mathrm{P}(\mathrm{mmol} / \mathrm{L})$ & $1.90 \pm 0.52$ & $1.84 \pm 0.56$ & $1.93 \pm 0.50$ \\
\hline PTH $(\mathrm{pg} / \mathrm{ml})^{\mathrm{a}}$ & $460.23(185.75-538)$ & $343.32(185.75-478.5)$ & $514.78(176.50-727.75)^{*}$ \\
\hline $\mathrm{SF}(\mathrm{ng} / \mathrm{ml})^{\mathrm{a}}$ & $410.59(112-528)$ & 349.64 (84.5-404.25) & $439.51(121-582)$ \\
\hline Serum iron (umol/L) ${ }^{a}$ & 10.99 (8.06-13.30) & $10.92(8.24-12.58)$ & $11.02(7.71-13.52)$ \\
\hline TIBC (umol/L) & $47.10 \pm 9.16$ & $46.95 \pm 9.65$ & $47.18 \pm 9.00$ \\
\hline Tch (mmol/L) & $3.90 \pm 0.99$ & $4.05 \pm 1.30$ & $3.83 \pm 0.79$ \\
\hline $\mathrm{TG}(\mathrm{mmol} / \mathrm{L})^{\mathrm{a}}$ & $1.51(0.90-1.80)$ & $1.74(1.02-1.74)$ & $1.41(0.85-1.82)$ \\
\hline LDL-C (mmol/L) & $2.20 \pm 0.71$ & $2.32 \pm 0.91$ & $2.14 \pm 0.59$ \\
\hline $\mathrm{HDL}-\mathrm{C}(\mathrm{mmol} / \mathrm{L})$ & $0.96 \pm 0.30$ & $0.91 \pm 0.20$ & $0.98 \pm 0.34$ \\
\hline ALB $(g / L)$ & $40.06 \pm 3.56$ & $39.14 \pm 3.13$ & $40.44 \pm 3.69$ \\
\hline
\end{tabular}

$\mathrm{Hb}$ hemoglobin, $\mathrm{Ca}$ calcium, $\mathrm{P}$ phosphate, $P T H$ parathyroid hormone, SF serum ferritin, $T I B C$ Total iron binding capacity, $T C h$ total cholesterol, $T G$ triglycerides, $L D L-$ $C$ low-density lipoprotein cholesterol, $H D L-C$ high-density lipoprotein cholesterol, $A L B$ albumin

${ }^{a}$ Median (25th-75th percentile). ${ }^{*} p<0.05 ;{ }^{* *} p<0.01$ 


\section{Serum klotho and cerebrovascular disease}

Cox regression analysis was used to explore the independent risk factors of cerebrovascular disease in hemodialysis patients (Table 2). The results showed that serum klotho $(\mathrm{HR}(95 \% \mathrm{CI})=0.975(0.960-0.990), \quad p=0.001) \quad$ and age $(\mathrm{HR}(95 \% \mathrm{CI})=1.104(1.038-1.174), \quad p=0.002) \quad$ were the independent risk factors of cerebrovascular disease in hemodialysis patients.

The ROC curve of klotho relation to cerebrovascular disease is depicted in Fig. 1. The area under the curve (AUC) for klotho and age was 0.728 (95\% CI: 0.624-0.831; $P=0.001$ ). The optimal cut-off value of serum klotho for predicting cerebrovascular disease was $137.22 \mathrm{pg} / \mathrm{ml}$, with a specificity of $96.4 \%$ and a sensitivity of $46.7 \%$.

\section{Correlations between the different parameters and klotho levels}

The correlations of serum klotho and different parameters are shown in Table 3. Whether in the crude model or after adjusted for age, serum klotho was not significantly correlation with different parameters of the calcium-phosphate axis, iron metabolism, lipid metabolism, hemoglobin and albumin. But the level of serum klotho was negative correlation with diabetes mellitus $(\mathrm{r}=-0.29, p=0.011)$,

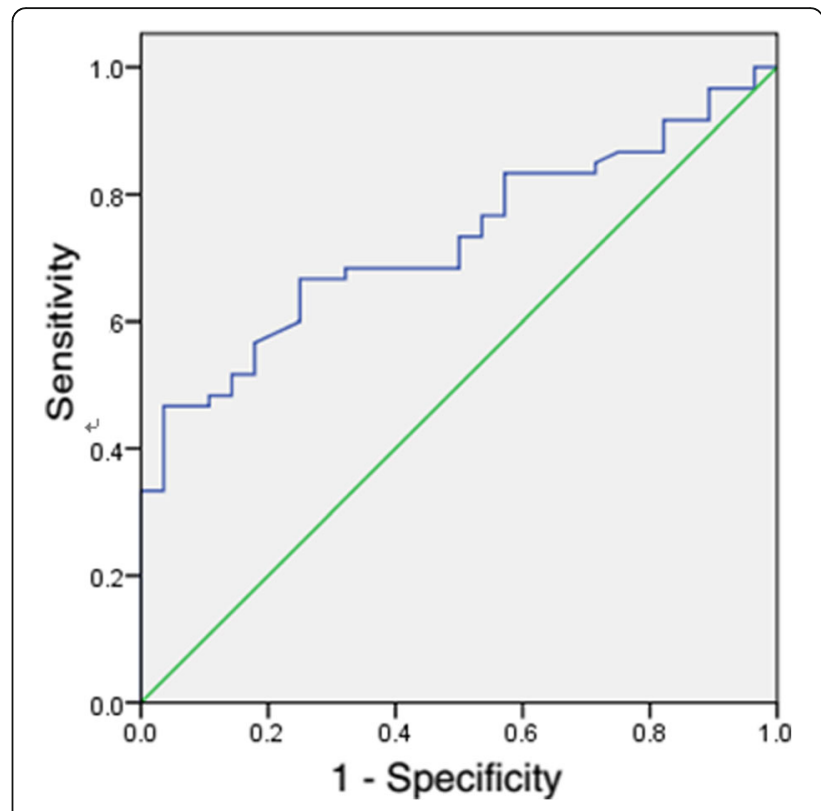

Fig. 1 ROC curves for serum klotho predicting CVD

Table 2 Cox regression analysis for incident cerebrovascular disease according to baseline variables among 88 hemodialysis patients

\begin{tabular}{|c|c|c|c|c|}
\hline & \multicolumn{2}{|l|}{ Univariable } & \multicolumn{2}{|l|}{ Multivariable } \\
\hline & $\mathrm{HR}(95 \% \mathrm{Cl})$ & $P$ & $\mathrm{HR}(95 \% \mathrm{Cl})$ & $P$ \\
\hline Age, years & $1.086(1.037-1.138)$ & $0.001^{* *}$ & $1.104(1.038-1.174)$ & $0.002^{* *}$ \\
\hline Male, n (\%) & $1.667(0.632-4.392)$ & 0.302 & & \\
\hline Diabetes history, n (\%) & $2.489(0.927-6.680)$ & 0.070 & & \\
\hline Hypertension, n (\%) & $1.500(0.437-5.148)$ & 0.519 & & \\
\hline Tobacco smoking, n (\%) & $1.083(0.297-3.951)$ & 0.904 & & \\
\hline HD vintage (months) & $1.027(1.002-1.053)$ & $0.033^{*}$ & $1.027(0.996-1.058)$ & 0.086 \\
\hline Klotho (pg/ml) & $0.977(0.965-0.990)$ & $0.001^{* *}$ & $0.975(0.960-0.990)$ & $0.001^{* *}$ \\
\hline $\mathrm{Hb}(\mathrm{g} / \mathrm{L})$ & $1.006(0.977-1.063)$ & 0.679 & & \\
\hline $\mathrm{Ca}(\mathrm{mmol} / \mathrm{L})$ & $1.298(0.217-7.772)$ & 0.775 & & \\
\hline$P(\mathrm{mmol} / \mathrm{L})$ & 0.707 (0.291-1.718) & 0.444 & & \\
\hline PTH (pg/ml) & 0.999 (0.997-1.000) & 0.095 & & \\
\hline $\mathrm{SF}(\mathrm{ng} / \mathrm{ml})$ & $0.996(0.909-1.091)$ & 0.931 & & \\
\hline Serum iron (umol/L) & $1.000(0.998-1.001)$ & 0.395 & & \\
\hline TIBC (umol/L) & 0.997 (0.949-1.048) & 0.913 & & \\
\hline Tch (mmol/L) & 1.249 (0.794-1.964) & 0.336 & & \\
\hline $\mathrm{TG}(\mathrm{mmol} / \mathrm{L})$ & $1.448(0.900-2.330)$ & 0.127 & & \\
\hline $\mathrm{LDL}-\mathrm{C}(\mathrm{mmol} / \mathrm{L})$ & $1.421(0.756-2.669)$ & 0.275 & & \\
\hline $\mathrm{HDL}-\mathrm{C}(\mathrm{mmol} / \mathrm{L})$ & $0.382(0.073-2.004)$ & 0.255 & & \\
\hline ALB (g/L) & 0.899 (0.778-1.038) & 0.145 & & \\
\hline
\end{tabular}

$\mathrm{Hb}$ hemoglobin, $\mathrm{Ca}$ calcium, $P$ phosphate, $P T H$ parathyroid hormone, SF serum ferritin, $T I B C$ Total iron binding capacity, $T c h$ total cholesterol, $T G$ triglycerides, $L D L-$ $C$ low-density lipoprotein cholesterol, $H D L-C$ high-density lipoprotein cholesterol, $A L B$ albumin, $H R$ hazard ratio, $95 \%$ CI $95 \%$ confidence interval ${ }^{*} p<0.05 ;{ }^{* *} \mathrm{p}<0.01$ 
Table 3 Correlations between the different parameters and klotho levels

\begin{tabular}{|c|c|c|c|c|}
\hline & \multicolumn{2}{|c|}{$\underline{\text { Crude Model }}$} & \multicolumn{2}{|c|}{ Adjusted for age } \\
\hline & $r$ & $p$ & $r$ & $p$ \\
\hline $\mathrm{Ca}(\mathrm{mmol} / \mathrm{L})$ & -0.121 & 0.282 & 0.012 & 0.942 \\
\hline $\mathrm{P}(\mathrm{mmol} / \mathrm{L})$ & 0.092 & 0.422 & -0.134 & 0.272 \\
\hline PTH (pg/ml) & 0.000 & 0.990 & 0.140 & 0.230 \\
\hline $\mathrm{Hb}(\mathrm{g} / \mathrm{L})$ & -0.090 & 0.370 & -0.070 & 0.570 \\
\hline $\mathrm{SF}(\mathrm{ng} / \mathrm{ml})$ & 0.032 & 0.810 & 0.170 & 0.172 \\
\hline Serum iron (umol/L) & -0.080 & 0.441 & -0.012 & 0.920 \\
\hline TIBC (umol/L) & -0.090 & 0.401 & -0.082 & 0.491 \\
\hline $\mathrm{TG}(\mathrm{mmol} / \mathrm{L})$ & -0.032 & 0.782 & -0.112 & 0.351 \\
\hline Tch (mmol/L) & -0.041 & 0.713 & -0.092 & 0.440 \\
\hline LDL-C (mmol/L) & 0.031 & 0.802 & -0.042 & 0.720 \\
\hline $\mathrm{HDL}-\mathrm{C}(\mathrm{mmol} / \mathrm{L})$ & -0.011 & 0.901 & -0.022 & 0.901 \\
\hline $\mathrm{ALB}(\mathrm{g} / \mathrm{L})$ & -0.092 & 0.461 & -0.090 & 0.430 \\
\hline DM history & -0.290 & $0.011^{*}$ & -2.980 & $0.013^{*}$ \\
\hline Hypertension & 0.012 & 0.910 & 0.012 & 0.910 \\
\hline Tobacco smoking & 0.110 & 0.310 & 0.123 & 0.253 \\
\hline
\end{tabular}

Ca calcium, $P$ phosphate, $P$ TH parathyroid hormone, $H b$ hemoglobin, SF serum ferritin, TIBC Total iron binding capacity, TG triglycerides, TCh total cholesterol, $L D L-C$ low-density lipoprotein cholesterol, $H D L-C$ high-density lipoprotein cholesterol, ALB albumin, DM diabetes mellitus. ${ }^{*} p<0.05$

and the correlation was remain unchanged after adjusted for age $(\mathrm{r}=-2.98, p=0.013)$.

\section{Serum klotho and cognitive function of patients with cerebrovascular disease}

The cognitive function of patients with cerebrovascular disease was assessed with a series of tests. The performance of each cognitive test was shown in Table 4. Compared to the patients with cerebral hemorrhage, the scores of each test in patients with cerebral infarction were not significantly difference.

In the crude model, serum klotho was not significantly correlation with the scores of HVLT-R, BVMT-R, VFT and Trail A. But after adjusted for age, the level of serum klotho was significantly correlated with the scores of VFT $(\mathrm{r}=0.539, p=0.021)$ (Table 5).
Table 5 Correlations between the klotho levels and the scores of each cognitive test

\begin{tabular}{|c|c|c|c|c|}
\hline & \multicolumn{2}{|c|}{ Crude model } & \multicolumn{2}{|c|}{ Adjusted for age } \\
\hline & $r$ & $p$ & $r$ & $p$ \\
\hline HVLT-R (Immediate recall) & 0.210 & 0.285 & 0.426 & 0.078 \\
\hline HVLT-R (Delayed recall) & 0.067 & 0.735 & 0.384 & 0.116 \\
\hline BVMT-R & 0.073 & 0.711 & 0.195 & 0.439 \\
\hline VFT & 0.252 & 0.235 & 0.539 & $0.021^{*}$ \\
\hline Trail A & -0.720 & 0.763 & -0.084 & 0.741 \\
\hline
\end{tabular}

HVLT-R Hopkins Verbal Learning Test-Revised, BVMT-R Brief Visuospatial Memory Test-Revised, VFT Verbal Fluency Test. ${ }^{*} p<0.05$

Seventeen cases with cerebral infarction and 5 cases with cerebral hemorrhage had cognitive impairment. Cox regression was used to assess the association between serum klotho and cognitive impairment of dialysis patients with cerebrovascular disease or cerebral infarction (Table 6). In all the patients with cerebrovascular disease or cerebral infarction, klotho was not significantly associated with cognitive impairment, neither in the crude model nor in the models adjusted for age and diabetes.

\section{Discussion}

The patients receiving maintain hemodialysis suffer from a serious threat of cerebrovascular disease [2]. It was reported that one-third of hemodialysis patients had experienced stroke symptoms. It means that, in addition to focus on the traditional risk factors for cerebrovascular disease, the exploration of new risk factors in dialysis patients is imminent. To our best knowledge, the current study is the first one to research the relationship between serum klotho level and cerebrovascular disease in hemodialysis patients.

The present study shows that decreased serum klotho concentration is the independently risk factor of cerebrovascular disease. Klotho, as a potential biomarker in renal disease [21], was decreased expression as the CKD progress and contribute to calcium and phosphorus metabolism. Decreased klotho protein expression possibly associated with vascular calcification and endothelial

Table 4 Cognitive function of cerebrovascular disease, cerebral infarction and cerebral hemorrhage;median (25th-75th percentile)

\begin{tabular}{llll}
\hline & Cerebrovascular disease $n=28$ & Cerebral infarction $n=23$ & Cerebral hemorrhage $n=5$ \\
\hline MMSE (total score) & $20.05(10.00-27.00)$ & $17.00(9.00-27.00)$ & $21.00(17.00-25.00)$ \\
HVLT-R (Immediate, words) & $3.00(1.00-5.00)$ & $3.35(2.00-5.00)$ & $1.40(0.00-3.00)$ \\
HVLT-R (Delayed, words) & $2.43(1.25-4.00)$ & $2.48(1.00-4.00)$ & $2.20(2.00-2.50)$ \\
BVMT-R (Immediate, figures) & $1.75(0.00-3.00)$ & $1.87(0.00-3.00)$ & $1.20(0.00-3.00)$ \\
VFT (animal, words) & $3.79(2.25-5.00)$ & $4.16(3.00-6.00)$ & $2.40(0.50-4.00)$ \\
Trail A (time, s) & $207.35(98.25-237.50)$ & $186.20(98.00-190.00)$ & $270.8(159.50-417.50)$
\end{tabular}


Table 6 Cox regression analysis the association between klotho and cognitive impairment of hemodialysis patients with cerebrovascular disease or cerebral infarction

\begin{tabular}{lllllllll}
\hline & \multicolumn{3}{l}{ Cerebrovascular disease } & & \multicolumn{3}{l}{ Cerebral infarction } \\
\cline { 2 - 3 } & HR & $95 \% \mathrm{Cl}$ & $P$ & & HR & $95 \% \mathrm{Cl}$ & $P$ \\
\hline Model 1 & 1.003 & $0.988-1.017$ & 0.732 & & 1.006 & $0.991-1.022$ & 0.417 \\
Model 2 & 1.002 & $0.987-1.017$ & 0.815 & & 1.005 & $0.988-1.021$ & 0.589 \\
Model 3 & 1.002 & $0.986-1.018$ & 0.776 & & 1.005 & $0.987-1.023$ & 0.576 \\
\hline
\end{tabular}

Model 1, crude model; Model 2, adjusted for age; Model 3, adjusted for age and diabetes

dysfunction, which might contribute to cerebrovascular disease [22-24].

Previous studies found that the suppressed expression of klotho was associated with klotho gene methylation through uremic toxins bound to DNA methyltransferase $[25,26]$. Klotho gene single nucleotide polymorphism (rs650439) has also been report to be associated with differing levels of circulating klotho and the onset of stroke [27]. Genetic variants of klotho have been associated with cerebrovascular disease [28-31]. In Chinese, the relationship between genetic variants of klotho and cerebrovascular disease needs to be explored.

We found that the level of serum klotho was negatively related with diabetes mellitus after adjusted for age. The previous study also found that serum klotho level was significantly decreased in T2DM patients compared to controls [32]. Further studies confirmed that $\beta$-cell-specific expression of klotho was associated with intracellular superoxide levels, oxidative damage, apoptosis, and DNAJC3 (a marker for endoplasmic reticulum stress) [33].

Dyslipidemia was the traditional risk factor for cerebrovascular disease. In the previous studies, plasma klotho was positively correlated with HDL-C [34], and there may have a functional interrelationship between them through insulin signaling, inhibition of apoptosis, or other mechanisms [35]. Metabolic disorders of calcium and phosphorus are common in hemodialysis patients, which always lead to vascular calcification and be closely related with cerebrovascular disease. Buiten MS et al reported that serum klotho was negatively correlated with PTH and $\mathrm{Ca}$ in hemodialysis patients [36]. But in the present study, there was no correlation between serum klotho and HDL-C, Ca, P, or PTH in hemodialysis patients. It may because our participants are limited. Whether circulating klotho concentration is associated with lipid, calcium and phosphorus levels in hemodialysis patients needs to be further explored in a large study.

Cognitive impairment is the common sequelae of cerebrovascular disease, especially in hemodialysis patients. In klotho mutant mice at the age of 7 wk., researchers found that long- but not short-term retention of novel object recognition memory is impaired, which was the role of oxidative stress [37]. In Japanese aged 60 or over, there were statistically significant differences in cognitive function for klotho gene promoter polymorphism G-395A. Subjects with the GG type at nucleotide - 395 had lower scores of cognitive function compared to the participants with the GA/AA type [38]. In the present study, serum klotho was correlated with verbal fluency after adjusted for age, but not memory or executive function. Cox regression suggested that serum klotho is not an independent risk factor of cognitive impairment for hemodialysis patients with cerebrovascular disease .

\section{Strengths and limitations of the study}

The present study is the first to show that serum klotho as a potential predictor of cerebrovascular disease in hemodialysis patients. But only 88 samples is our limitation. Large samples of prospective studies are needed to certify our results. Further studies are needed to explore the reason for the serum klotho decline in hemodialysis patients. Prospective studies will be needed to determine whether treatment of klotho deficiency may be a promising strategy to decrease the burden of comorbidity in hemodialysis patients.

\section{Conclusions}

The serum klotho level is a potential predictor of cerebrovascular disease in hemodialysis patients, but it is not an independent risk factor of cognitive impairment for hemodialysis patients with cerebrovascular disease.

\section{Abbreviations \\ 95\% Cl: 95\% confidence interval; ALB: Albumin; BVMT-R: Brief Visuospatial Memory Test-Revised; Ca: Calcium; CKD: Chronic kidney disease; CVD: cardiovascular disease; DM: Diabetes mellitus; ESRD: End-stage renal disease; Hb: Hemoglobin; HDL-C: High-density lipoprotein cholesterol; HR: hazard ratio; HVLT-R: Hopkins Verbal Learning Test-Revised; LDL-C: Low- density lipoprotein cholesterol; MMSE: Mini-mental state examination; P: Phosphate; PTH: Parathyroid hormone; SBI: silent brain infarction; SF: Serum ferritin; Tch: Total cholesterol; TG: Triglycerides; TIBC: Total iron binding capacity; VFT: Verbal Fluency Test}

\section{Acknowledgements}

Not applicable.

\section{Funding}

This work was supported by Hubei Province Natural Science Fund 2014CFC1047 and Wuhan Health and Family Planning Commission research projects WG15A02, WX18Q31. These funds are responsible for funding support, guiding the research design and supervising the research process.

\section{Availability of data and materials}

Because the raw data of this article is a part of a big project, so we can't share it temporarily. Two years later, the raw data can be available from the corresponding author on reasonable request.

\section{Consent to publish}

Not applicable.

\section{Authors' contributions}

DJW designed the study and revised the manuscript critically for important intellectual content. WHL and LH made substantial contributions to 
conception and draft the manuscript. SXH performed the serum klotho levels examination by ELISA. DXG and CY performed CT and MRI scans and collected the results. LCX and DLP evaluated the cognitive function of hemodialysis patients with cerebrovascular disease. All authors read the manuscript, approved the final version and agreed to be accountable for al aspects of the work in ensuring that questions related to the accuracy or integrity of any part of the work are appropriately investigated and resolved.

\section{Ethics approval and consent to participate}

The Biological and Medical Ethics Committee of Puai Hospital, Tongji Medical College, Huazhong University of Science and Technology (Wuhan, China) approved the study. All participants have written informed consent before the study.

\section{Competing interests}

The authors declare that they have no competing interests.

\section{Publisher's Note}

Springer Nature remains neutral with regard to jurisdictional claims in published maps and institutional affiliations.

\section{Received: 5 December 2017 Accepted: 25 January 2019} Published online: 21 February 2019

\section{References}

1. Zhang L, Wang F, Wang L, Wang W, Liu B, Liu J, Chen M, He Q, Liao Y, Yu X, Chen N, Zhang JE, Hu Z, Liu F, Hong D, Ma L, Liu H, Zhou X, Chen J, Pan L, Chen W, Wang W, Li X, Wang H. Prevalence of chronic kidney disease in China: a cross-sectional survey. Lancet. 2012;379(9818):815-22.

2. Seliger SL, Gillen DL, Longstreth WT Jr, Kestenbaum B, Stehman-Breen CO. Elevated risk of stroke among patients with end-stage renal disease. Kidney Int. 2003;64(2):603-9

3. U.S. Renal Data System. USRDS 2007 Annual Data Report: Atlas of Chronic Kidney Disease and End-Stage Renal Disease in the United States. Bethesda: National Institutes of Health, National Institute of Diabetes and Digestive and Kidney Diseases; 2007.

4. Sozio SM, Armstrong PA, Coresh J, Jaar BG, Fink NE, Plantinga LC, Powe NR, Parekh RS. Cerebrovascular disease incidence, characteristics, and outcomes in patients initiating dialysis: the choices for healthy outcomes in caring for ESRD (CHOICE) study. Am J Kidney Dis. 2009;54(3):468-77.

5. Delmez JA, Yan G, Bailey J, Beck GJ, Beddhu S, Cheung AK, Kaysen GA, Levey AS, Sarnak MJ, Schwab SJ. Hemodialysis (HEMO) Study Group. Cerebrovascular disease in maintenance hemodialysis patients: results of the HEMO study. Am J Kidney Dis. 2006:47(1):131-8.

6. Kurella Tamura M, Meyer JB, Saxena AB, Huh JW, Wadley VG, Schiller B. Prevalence and significance of stroke symptoms among patients receiving maintenance dialysis. Neurology. 2012;79(10):981-7.

7. Abramson JL, Jurkovitz CT, Vaccarino V, Weintraub WS, McClellan W. Chronic kidney disease, anemia, and incident stroke in a middle-aged, communitybased population: the ARIC study. Kidney Int. 2003;64(2):610-5.

8. Toyoda K, Fujii K, Fujimi S, Kumai Y, Tsuchimochi H, lbayashi S, lida M. Stroke in patients on maintenance hemodialysis: a 22-year single-center study. Am J Kidney Dis. 2005;45:1058-66.

9. Imura A, Iwano A, Tohyama O, Tsuji Y, Nozaki K, Hashimoto N, Fujimori T, Nabeshima Y. Secreted klotho protein in sera and CSF: implication for posttranslational cleavage in release of klotho protein from cell membrane. FEBS Lett. 2004;565(1-3):143-7.

10. Chang Q, Hoefs S, van der Kemp AW, Topala CN, Bindels RJ, Hoenderop JG. The beta-glucuronidase klotho hydrolyzes and activates the TRPV5 channel. Science. 2005;310(5747):490-3.

11. Hu MC, Shi M, Zhang J, Pastor J, Nakatani T, Lanske B, Razzaque MS, Rosenblatt KP, Baum MG, Kuro-o M, Moe OW. Klotho: a novel phosphaturic substance acting as an autocrine enzyme in the renal proximal tubule. FASEB J. 2010:24(9):3438-50.

12. Lim K, Lu TS, Molostvov G, Lee C, Lam FT, Zehnder D, Hsiao LL. Vascular klotho deficiency potentiates the development of human artery calcification and mediates resistance to fibroblast growth factor 23. Circulation. 2012; 125(18):2243-55.

13. Yamamoto M, Clark JD, Pastor JV, Gurnani P, Nandi A, Kurosu H, Miyoshi M, Ogawa Y, Castrillon DH, Rosenblatt KP, Kuro-o M. Regulation of oxidative stress by the anti-aging hormone klotho. J Biol Chem. 2005;280(45):38029-34.
14. Pavik I, Jaeger P, Ebner L, Wagner CA, Petzold K, Spichtig D, Poster D, Wüthrich RP, Russmann S, Serra AL. Secreted klotho and FGF23 in chronic kidney disease stage 1 to 5: a sequence suggested from a cross-sectional study. Nephrol Dial Transplant. 2013 Feb;28(2):352-9.

15. Yamazaki Y, Imura A, Urakawa I, Shimada T, Murakami J, Aono Y, Hasegawa H, Yamashita T, Nakatani K, Saito Y, Okamoto N, Kurumatani N, Namba N, Kitaoka T, Ozono K, Sakai T, Hataya H, Ichikawa S, Imel EA, Econs MJ, Nabeshima Y. Establishment of sandwich ELISA for soluble alpha-klotho measurement: age-dependent change of soluble alpha-klotho levels in healthy subjects. Biochem Biophys Res Commun. 2010;398(3):513-8.

16. Brandt J, Benedict RHB. Hopkins verbal learning test-revised. Profes-sional manual. Lutz: Psychological Assessment Resources, Inc; 2001.

17. Benedict RH. Brief visuospatial memory test—revised. Professional manual. Lutz: Psychological Assessment Resources, Inc; 1997.

18. D'Elia LF, Satz P, Lyons Uchiyama CL, White T. Color trails test. Professional manual. Lutz: Psychological Assessment Resources Inc.; 1996.

19. Benton AL, Hamsher K. Multilingual Aphasia Examination Manual (revised). lowa City: University of lowa; 1978.

20. Murray AM, Tupper DE, Knopman DS, Gilbertson DT, Pederson SL, Li S, Smith GE, Hochhalter AK, Collins AJ, Kane RL. Cognitive impairment in hemodialysis patients is common. Neurology. 2006;67(2):216-23.

21. Neyra JA, Hu MC. Potential application of klotho in human chronic kidney disease. Bone. 2017 Jul;100:41-9.

22. Craver L, Dusso A, Martinez-Alonso M, Sarro F, Valdivielso JM, Fernández E. A low fractional excretion of phosphate/Fgf23 ratio is associated with severe abdominal aortic calcification in stage 3 and 4 kidney disease patients. BMC Nephrol. 2013;14:221.

23. Lindberg $K$, Olauson H, Amin R, Ponnusamy A, Goetz R, Taylor RF, Mohammadi M, Canfield A, Kublickiene K, Larsson TE. Arterial klotho expression and FGF23 effects on vascular calcification and function. PLoS One. 2013;8(4):e60658

24. Hu MC, Shi M, Zhang J, Quiñones H, Griffith C, Kuro-o M, Moe OW. Klotho deficiency causes vascular calcification in chronic kidney disease. J Am Soc Nephrol. 2011 Jan:22(1):124-36.

25. Young GH, Wu VC. KLOTHO methylation is linked to uremic toxins and chronic kidney disease. Kidney Int. 2012;81(7):611-2.

26. Sun CY, Chang SC, Wu MS. Suppression of klotho expression by proteinbound uremic toxins is associated with increased DNA methyltransferase expression and DNA hypermethylation. Kidney Int. 2012;81(7):640-50.

27. Oguro O, Kamide K, Ito N, Nakama C, Kawai T, Takeya Y, Yamamoto K, Sugimoto K, Ikebe K, Gondo Y, Ohishi M, Rakugi H. Klotho gene single nucleotide polymorphism is associated with the onset of stroke, hypertensive organ damages, and plasma klotho protein concentration. Eur Geriatr Med. 2013;4:S101-2

28. Majumdar V, Nagaraja D, Christopher R. Association of the functional KL-VS variant ofKlothogene with early-onset ischemic stroke. Biochem Biophys Res Commun. 2010:403(3-4):412-6.

29. Arking DE, Atzmon G, Arking A, Barzilai N, Dietz HC. Association between a functional variant of the KLOTHO gene and high-density lipoprotein cholesterol, blood pressure, stroke, and longevity. Circ Res. 2005;96:412-8.

30. Kim Y, Kim JH, Nam YJ, Kong M, Kim YJ, Yu KH, Lee BC, Lee C. Klotho is a genetic risk factor for ischemic stroke caused by cardioembolism in Korean females. Neurosci Lett. 2006:407:189-94.

31. Majumdar V, Nagaraja D. Christopher R. Is the F352V variant of klotho a risk predictor for stroke in the young? Atheroscler Suppl. 2009:10(2):880.

32. Wu C, Wang Q, Lv C, Qin N, Lei S, Yuan Q, Wang G. The changes of serum sKlotho and NGAL levels and their correlation in type 2 diabetes mellituspatients with different stages of urinary albumin. Diabetes Res Clin Pract. 2014;106(2):343-50.

33. Lin $Y$, Sun Z. In vivo pancreatic $\beta$-cell-specific expression of antiaging gene Klotho: a novel approach for preserving $\beta$-cells in type 2 diabetes. Diabetes. 2015:64(4):1444-58

34. Semba RD, Cappola AR, Sun K, Bandinelli S, Dalal M, Crasto C, Guralnik JM, Ferrucci L. Plasma klotho and cardiovascular disease in adults. J Am Geriatr Soc. 2011;59(9):1596-601

35. Walter M. Interrelationships among HDL metabolism, aging, and atherosclerosis. Arterioscler Thromb Vasc Biol. 2009;29(9):1244-50

36. Gonçalves FLC, Elias RM, dos Reis LM, Graciolli FG, Zampieri FG, Oliveira RB, Jorgetti V, Moysés RMA. Soluble klotho is not independently associated with cardiovascular disease in a population of dialysis patients. BMC Nephrol. 2014;15:197. 
37. Nagai T, Yamada K, Kim HC, Kim YS, Noda Y, Imura A, Nabeshima Y, Nabeshima T. Cognition impairment in the genetic model of aging klotho gene mutant mice: a role of oxidative stress. FASEB J. 2003;17(1):50-2.

38. Shimokata $\mathrm{H}$, Ando F, Fukukawa Y, Fukukawa Y, Nishita Y. Klotho gene promoter polymorphism and cognitive impairment. Geriatr Gerontol Int. 2006;6:136-41.

Ready to submit your research? Choose BMC and benefit from:

- fast, convenient online submission

- thorough peer review by experienced researchers in your field

- rapid publication on acceptance

- support for research data, including large and complex data types

- gold Open Access which fosters wider collaboration and increased citations

- maximum visibility for your research: over $100 \mathrm{M}$ website views per year

At $B M C$, research is always in progress.

Learn more biomedcentral.com/submissions 